Journal of Balkumari College

ISSN : 2467-9321 Website: http://www.nepjol.info/index.php/jbkc

Volume : 9, Issue : 1, June 2020, Page No.: 55-58

\title{
Cognitive Impairment in Alcoholic Addicts
}

\author{
Dr. Mahesh Kumar Gajurel* \\ M.Ed., M.A., M. Phil. \\ Clinical Psychology \\ PHD Health Education \\ Lecturer, Balkumari College, Chitwan, Nepal
}

\begin{abstract}
This present study was intended examine cognitive impairment in alcoholic addicts. The sample of study comprised of one group male alcoholic addicts $(\mathrm{N}=100)$ and one group of comparative matched non addict norma $(\mathrm{N}=100)$. The subjects were assessed to measure visual reproduction, visual recognition, immediate recall and delayed recall. Test scores were analyzed using one way ANOVA,. Results revealed significant differences between alcohol addicts and non addicts testifying memory impairment among alcohol addicts
\end{abstract}

Key Words: Alcohol addicts, memory impairment.

\section{INTRODUCTION}

Drug abuse in one of the perennial and pervasive problems that countries all over the world have are facing for centuries. Seeing through the personal, interpersonal and socio-cultural problems it leads to behavioral problems. The practice of drug alcohol abuse leads to physical and psychological damages. Physiological deterioration caused by addiction of drug alcohol have not been explored and identified substantially to the extent physical damages have been reported.

Alcohol dependence syndrome as the world health organization prefers the term to define, a psychic and physical state resulting from taking alcohol......... include a compulsion to take alcohol on a continuous or periodic basis in order to experience its psychic effect and sometimes to avoid the discomfort of its absence........" (W.H.O. 1992). Alcohol is all sky group with Hydroxyl (OH) group attached alcohol (Ethanal) has within structure the chemical power it depress the action of central nervous system. Thus it can definitely be classified as mind-altering drug. Primarily it is depressant but in small quality it can act as a stimulant as well as tranquilizer. It has complex contradictory effected on the brain. It is both a nervous system stimulant and depressant. It activates the brains pleasure areas which release endogenous hormones. (Browns, 1996, Van Ree, 1996). Besides this stimulation role alcohol depresses brain functioning of the higher brain centers inhibiting ghitamate, an excitatory neurotransmitter impairment of learning ability, judgment and other rational processes and low motor coordination and self control are some of the results of inhibitory of effects of ghitamate. The intake produces physiological and psychological dependence.

Tamkin and Dolenz (1990) have replicated the finding of Tamkin (1983) study. The authors used weighttest result to examine various types of cognitive impairment in alcoholic addicts relatives to their published norms. The sample of study were 104 male alcoholics in an alcohol rehabilitation unit. The study used the weigh colour from sorting test west. Adult intelligence scale (WAIS) and Trials A and B of the Halosted Neuropsychological test battery. The alcoholic group was reported to be cognitively impaired and differed from norms an Trials A and B and the WAIS subtests of unable to shift concepts on the weigh the addicts not differ significantly from that study.

Narang, Prasad, Gupta and Garg (1991) Obtained significant relationship between cognitive impairment and duration of alcohol use. The cognitive impairment increase with the duration of alcohol use. There were significant differences terms of between alcoholics and their matched controls in terms of cognitive functions.

Nixon (1994) reviewed the studies of neuropsychological consequence of long term alcohol in women.

\footnotetext{
$\bar{*}$ Corresponding author: mkgajurel@gmail.com
} 
Alcoholic women over a wide range of neuropsychological domains, were reported to be a adversely affected by long term alcohol abuse include perceptual motor skills. Visuospatial processes, learning memory and abstract problem solving, Alcohol men and women are impaired to similar degree.

Beatly (1995) observed the neuropsychological performance of cocaine abusers who had been abstinent for 24-40 days was compared with 22 normal and 24 recently abstinent alcoholics. with alcoholic and cocaine abusers performed significally. More poorly than control on most measures of learning and memory. Problem solving and abstraction and preceptor motor abusers O' Mahany and Doherty (1996) studied adequately detoxified hospital treated alcohol abusers. They were neuropsychologically assessed for alcohol-related cognitive impatient. Both group manifested the commonly found impairments on the Wechsler adult intelligence scale $(\mathrm{N}=50)$ and the revised Wechsler adult insentience scale $(\mathrm{N}=44)$. In addition, and almost identical pattern of substantial impairment was found when both groups were examined by Russels (1975) 1988 version of the logical memory and visual reproduction subtests of the Wechsler memory scale. A clear pattern of memory impairment for both verbal and non-verbal memory was found.

Beatly (1997) investigated the effect of combined abuse of alcohol and other drugs on several tests of visuospatial cognition by comparing 94 adults, Eight five who had abused only alcohol and marijuana, or alcohol and multiple other drugs with 35 adults. Community controls testing was done after 3 weeks of treatment for the drug abuses on all measures of visuospatial learning and memory. All the groups of alcohol were found impaired relative to their matched controls counterparts.

Hoaken, Assed \& Pihl (1998) have investigated whether subjects with above average cognitive functioning would. When intoxicated inhabit aggression in order to attain monetary reward 43 men. age 18-30 years. selected on the basis of high performance on the neuropsychological test putatively assessing learning task, participated in a modified version of the Tyler aggression task. Half the subjects were actually alcohol intoxicated. The other half were contingent monitory reward for choosing lower shocks. Aggression was defined as sharps intensity delivered to a sham opponent. Contrary to the hypothesis intoxicated subjects. When through significantly impaired cognitively relative to their non intoxicated peers to have no difficulty inhibiting their aggression in order to gain monetary reward. That is, there was no difference between intoxication and non-intoxication. Subjects on the dependent variable shock intensity. When contingent money was available.

Lippas,et.al. 2005 have studied 40 male and 37 female (man age 63yrs) Greek alcohol, patients and an equal number of control subjects. Both groups were evaluated with the mini mental state examination, the syndrome short, test, the verbal fluency test (category and latter) the clock-test and the digit span (forward \& backward) from the Wechsler Adult intelligence scale and revised), Alcohol patients had statically significant lower score on all scales.

Alcoholics are not all alike in terms of the degrees of impairment alcohol causes on the brain but most alcoholics with cognitive impairment show improvement in brain structure and functioning with a year of sobriety story Barnes (2011), effects of alcohol on the Brain Drug Addition treatment News. The aim of the present study was to ascertain whether cognitive impairment in alcoholic addicts are pervasive or specific to one aspect of memory, such as, visual reproduction visual recognition, Immediate Recall and Delayed Recall.

\section{Hypothesis}

Mean scores of visual reproduction visual recognition. Immediate Recall and Delayed Recall of alcohol addicts would be lower than their normal control counterparts.

\section{METHODOLOGY}

The sample of study consisted of 200 male subject of 20 to 40 age group, addicted to alcohol $(\mathrm{N}=100)$ and non-addict control $(\mathrm{N}=100)$ the addicts were selected from drug de addicts centre Chitwan The criteria of inclusion of alcohol addicts was the sample of control group was selected from different collages Bharatpur Metropolitan City, the inclusion criteria for the control group (the Non addicts group) was demographically matched subjects who were not habituated with any type of drug-Cigarette, Smoking and even Chewing Pan or Tobacco. 
Tools- The following tools were used for the present study.

\section{Wechsler Memory scale (Adopted Hindi version by Dwivedi et.al, 1997)}

The scale that measures memory function visual reproduction, visual recognition, immediate recall and delayed recall was administered on both the alcohol addict and non addict samples to assess their memory ability in 4 dimensions.

Procedure- In the beginning the personal information about the subjects were recorded. There after the Hindi adaptation of Wechsler memory scale (1997) that measures visual reproduction. Visual recognition. Immediate recall and delayed recall subscales was administered on the subjects. In the visual reproduction measures subjects were shown three cards with sample figures for ten seconds each. Subjects had to draw the figure on a sheet of plain paper placed in front after the removal of the cords first and second card contained figure each while the third card contained 2 figures. After the initial measures subjects had to reproduce the number of required to recognize these target photographs from an array to test photograph. Subjects had to identify these photograph with the redmark. If the subject recognized less than four figures. He was encouraged to guess and was allowed to make a record of self corrections. In the third step a brief paragraph containing 3 or 4 lines was orolly presented to the subject and they had to recall it. Two short stories were presented for immediate recall. A verbatim recall of short stories were instructed from the subjects. Responses was made for coding purpose. This step was followed by an internal of 30 minutes. In the final step. The subjects had to present both the stories on by one with all the details failing which they were given clue.

\section{RESULTS}

Table1: means and SD on the four subscales of scores of alcohol addict and normal controls

\begin{tabular}{|l|c|c|c|c|c|c|c|c|}
\hline & VR Mean & SD & VRC Man & SD & IR Mean & SD & DR Mean & SD \\
\hline Normal Group & 12.60 & 1.36 & 16.77 & 1.35 & 37.19 & 4.37 & 35.96 & 4.67 \\
\hline Alcohol addicts & 10.81 & 1.15 & 10.55 & 2.52 & 23.32 & 4.00 & 20.39 & 3.91 \\
\hline
\end{tabular}

Table 1 shows that the means scores of alcohol addicts for the four dimensions of memory viz, visual reproduction, visual recognition, immediate recall, delayed recall are substantially lower than their matched non addict controls. SD scores for the four memory measures indicate that both the alcohol addict and non addict control groups are homogeneous in terms of the memory scores.

Table 2 - Summary of analysis of variance (ANOVA) on was scores for the alcohol and normal controls

\begin{tabular}{|c|c|c|c|c|c|}
\hline Source of variation Wechsler memory scale & SS & DT & MS & $\mathrm{F}$ & P Sig. \\
\hline Visual reproduction & \multirow[b]{2}{*}{$\begin{array}{c}1104.500 \\
606.680 \\
1711.180\end{array}$} & \multirow[b]{2}{*}{$\begin{array}{c}1 \\
198 \\
199\end{array}$} & \multirow[b]{2}{*}{$\begin{array}{c}1104.500 \\
3.064\end{array}$} & \multirow[b]{2}{*}{36.472} & \multirow[b]{2}{*}{.000 (Sig) } \\
\hline $\begin{array}{l}\text { Between group } \\
\text { Within Group } \\
\text { Total }\end{array}$ & & & & & \\
\hline Visual recognition & \multirow[b]{2}{*}{$\begin{array}{c}1934.420 \\
812.460 \\
2746.880\end{array}$} & \multirow[b]{2}{*}{$\begin{array}{c}1 \\
198 \\
199 \\
\end{array}$} & \multirow[b]{2}{*}{$\begin{array}{c}1934.420 \\
4.103\end{array}$} & \multirow[b]{2}{*}{471.426} & \multirow[b]{2}{*}{$.000(\mathrm{Sig})$} \\
\hline $\begin{array}{l}\text { Between group } \\
\text { Within Group } \\
\text { Total }\end{array}$ & & & & & \\
\hline Immediate Recall & \multirow[b]{2}{*}{$\begin{array}{c}9618.845 \\
3473.150 \\
13091.995\end{array}$} & \multirow[b]{2}{*}{$\begin{array}{c}1 \\
198 \\
199\end{array}$} & \multirow[b]{2}{*}{$\begin{array}{c}9618.845 \\
17.541\end{array}$} & \multirow[b]{2}{*}{548.368} & \multirow[b]{2}{*}{$.000(\mathrm{Sig})$} \\
\hline $\begin{array}{l}\text { Between group } \\
\text { Within Group } \\
\text { Total }\end{array}$ & & & & & \\
\hline Delayed Recall & \multirow[b]{2}{*}{$\begin{array}{c}12121.245 \\
3673.60 \\
15794.875\end{array}$} & \multirow[b]{2}{*}{$\begin{array}{c}1 \\
198 \\
199\end{array}$} & \multirow[b]{2}{*}{$\begin{array}{c}12121.245 \\
18.554\end{array}$} & \multirow[b]{2}{*}{653.307} & \multirow[b]{2}{*}{$.000(\mathrm{Sig})$} \\
\hline $\begin{array}{l}\text { Between group } \\
\text { Within Group } \\
\text { Total }\end{array}$ & & & & & \\
\hline
\end{tabular}


Table 2 reports highly significant values on all the four dimensions of memory measures of alcohol addict and non addict groups. Stable lower scores in the measurement of various memory in at the cognitive impairment of alcohol addicts. Thus assessments hypothesis framed for the study stands accepted.

\section{DISCUSSION}

Findings of the study indicated that alcohol addicts were significantly impaired in all subtests of Wechsler memory scale as compared to normal controls. Such finding was substantiated by earlier observation of Narang, et. al, (1991). In the present investigation subjects included in the alcohol addict sample had a minimum history of consuming alcohol for the last 4 years. After abstinence of 24 to 40 days the influence of cognitive impairment reported in alcohol addicts on all the measures of learning, memory, problem solving, abstraction percepto motor skills, when compared with controls (Beatly, et. al. 1995). Available literature established that the ability to recall past events is also greatly affected by alcohol consumption, though present investigation concentrated only on immediate and delayed recall as well as visual reproduction and recognition. Memory loss can be considered as a warming sign that alcohol consumption has reached to excessive level and if remain untreated permanent damage of brain may produce long lasting effect on memory. The degree of brain impairment are not alike in all the alcohol addicts. Recent approach assures of improvement in cognitive structure and functioning of brain damage impairs the cognitive functions (within on year of withdrawal of alcohol) (Barners, 2011). Variety of treatment programs such as, detox, counseling, group and individual therapy and family involvement have reported positive results in de addiction of alcohol abuses.

\section{CONCLUSION}

An early rehabilitation is suggested for the subjects who show memory deficit to avoid any long lasting damage and memory loss.

\section{REFERENCES}

Barnes, S (2011), Effects of alcohol on the Brain Drug addiction Treatment News.

Beatly, w.W., Katzung, V.M, Moreland, V.J. and Nixon, S. (1995) Neuropsychological performance of recently abstinent alcoholics and cocaine abusers. Drug \& Alcohol dependence, 3,247-253.

Beatly, W., Balance, C.r. Hames, K.A. \& Nixon, S. (1997), spatial cognition in alcoholics: influence of concurrent absuse of other drugs. Drugs and Alcohol Dependence, 3,167-174.

Braun, S. (1996). Buzz. New York: Oxford University Press.

Dwivedi, C.B., Pandey, R., Gopalji, S., Pathak, K.S. \& Mandal, M.K. (1997). Hindi adaptation of subscales of Wechsler memory scale. Unpublished manuscript. Department of Psychology, B.H.U. Varanasi.

Hoaken, P.M.S., Assed, J.M., \& Pihl., R.O. ( 1998), cognitive functioning and the inhibition of alcohol induced aggression. Journal of studies on alcohol, 5,599-607.

Liapass, I. oannis, Theatoka, I. Oulia, Kapaki, Elisabeth: Ilias, I oannis et. al. (2005) Neuropsychological correlates of Greek Alcoholic Patients WHO reprts memory disturbance, Psychological Reprts, 96, 197-203.

Narang, R.L. Prasad, D., Gupta., R \& Gerg, D. (1991). Cognitive dysfunction of alcoholics. Indian journal of psychiatry, 4,297-301.

Nixon, S. (1994), Cognitive deficits in alcoholic women, special foucus women and alcohol, alcohol health and research world, 4, 228-232.

O' Mahony, J.F., Doherty, B. (1996) . Intellectual impairment among recent abstiment alcohol abuse. British Journal of Clinical Psychology, 1, 77-83.

Tamkin, A.S., Dolenz., J.J. (1990), Cognitive impairment in alcoholics, perception and motor skills, 70,816-818.

Van Ree, J.M. (1996), Endorphins and experimental addiction. Alcohol, 13,25-30.

World Health Organization, (1992), ICD-10 classification of mental and behavioral disorders: clinical descriptions and diagnostic guidelines, Geneva, Author. 